\title{
Treg/Th17 imbalance in malignant pleural effusion partially predicts poor prognosis
}

\author{
GUANGDIE YANG, HEQUAN LI, YINAN YAO, FEI XU, ZHANG BAO and JIANYING ZHOU
}

Department of Respiratory Diseases, First Affiliated Hospital of Zhejiang University, Hangzhou, Zhejiang 310003, P.R. China

Received September 12, 2014; Accepted October 20, 2014

DOI: $10.3892 /$ or.2014.3576

\begin{abstract}
Accumulating evidence shows that an imbalance in regulatory $\mathrm{T}$ cells (Tregs)/T helper IL-17-producing cells (Th17) exists in malignant pleural effusion (MPE). However, the cause of this phenomenon in MPE and the underlying mechanism remain uncertain. The percentages of Tregs and Th17 cells in MPE and parapneumonic effusion (PPE) were determined by flow cytometry. Their specific transcription factors, forkhead box P3 (FoxP3) and retinoic acid-related orphan receptor $\gamma \mathrm{t}(\mathrm{ROR} \gamma \mathrm{t})$; related cytokines, interleukin-6 (IL-6), IL-17, IL-10, and transforming growth factor- $\beta 1$ (TGF- $\beta 1$ ); and chemokines, $\mathrm{C}-\mathrm{C}$ motif ligand 17 (CCL17) and CCL20, were analyzed by real-time PCR and ELISA, respectively. Compared to patients with PPE, patients with MPE presented a higher percentage of Tregs but a lower frequency of Th17 cells. Foxp3 mRNA expression level in the cells in the pleural effusion was significantly increased in patients with MPE compared to the levels in patients with PPE (MPE vs. PPE: $3.05 \pm 0.62$ vs. $0.52 \pm 0.11, \mathrm{P}=0.0012$ ). It was also noted that high levels of IL-10, TGF- $\beta 1$ and CCL17 were observed in MPE when compared to PPE (MPE vs. PPE: IL- $10,166.3 \pm 39.53$ vs. $40.38 \pm 10.92$ pg/ml, $\mathrm{P}=0.0307$; TGF- $\beta 1$, $10,720 \pm 1,274$ vs. $1,747 \pm 293.2 \mathrm{pg} / \mathrm{ml}, \mathrm{P}<0.0001$; CCL17, $341.1 \pm 88.22$ vs. $119.2 \pm 19.80 \mathrm{pg} / \mathrm{ml}, \mathrm{P}=0.0427)$. Furthermore, a high ratio of Tregs/Th17 cells in MPE was highly correlated to poor survival. An alteration in CCL17 and CCL20 might contribute to the Treg/Th17 imbalance in MPE, which partially predicts a poor prognosis in patients with lung cancer.
\end{abstract}

\section{Introduction}

Malignant pleural effusion (MPE) is a common and devastating complication of various advanced malignancies, of

Correspondence to: Professor Jianying Zhou or Dr Hequan Li, Department of Respiratory Diseases, First Affiliated Hospital of Zhejiang University, 79 Qingchun Road, Hangzhou, Zhejiang 310003, P.R. China

E-mail: zjyhz@zju.edu.cn

E-mail: lihequan@zju.edu.cn

Key words: Treg cells, Th17 cells, malignant pleural effusion, parapneumonic effusion, imbalance, survival which lung cancer is the most common cause, accounting for one-third of patients (1). The incidence of MPE parallels that of lung cancer and its presence impedes effective surgery and is predictive of poor prognosis, with a short median survival after MPE diagnosis between 4 and 9 months (2). It has been well demonstrated that $\mathrm{CD} 4^{+} \mathrm{T}$ lymphocytes frequently accumulate in MPE secondary to direct pleural invasion from malignant tumors $(3,4)$. More recently, two subsets of $\mathrm{CD}^{+} \mathrm{T}$ cell, regulatory $\mathrm{T}$ cells (Tregs) and $\mathrm{T}$ helper IL-17-producing (Th17) cells, have attracted much attention in MPE.

Previous evidence suggests that Tregs, characteristically expressing Foxp3 (5), are essential for maintainance of selftolerance and exert a potential for inhibiting effector $\mathrm{T}$ cells, by a cell contact-manner or by secreting inhibitory cytokines, such as interleukin-10 (IL-10) and transforming growth factor- $\beta 1$ TGF- $\beta$ (6). Importantly, Tregs may function as an independent prognostic factor in several types of cancers and are alternately harmful or beneficial to patient survival (7). Similar to Tregs, Th17 cells express retinoic acid-related orphan receptor $\gamma \mathrm{t}(\mathrm{ROR} \gamma \mathrm{t})$ and release pro-inflammatory cytokines, and are involved in the development of autoimmune and tumor diseases (8). Controversially, Th17 cells have been found in both pro- and antitumorigenic processes $(9,10)$. Previous studies have demonstrated that increased Tregs are recruited into the pleural space in MPE induced by chemokine C-C motif ligand 22 (CCL22) (8), whereas the number of Th17 cells are elevated in MPE and such an elevation predicts improved survival of patients with MPE (11).

In the present study, we compared the frequency of Tregs and Th17 cells, mRNA expression of relevant transcription factors, their hallmark cytokines and related chemokines between MPE and parapneumonic effusion (PPE), to investigate the role of Treg/Th17 imbalance in MPE. A higher percentage of Tregs and a lower percentage of Th17 cells were found in MPE in contrast to these percentages in PPE, accompanied by increased levels of FoxP3 mRNA and concentrations of IL-10 and TGF- $\beta$. Moreover, an alteration of CCL17 and CCL20 might be responsible for the Treg/Th17 imbalance in MPE. Furthermore, an elevated Treg/Th17 ratio was predictive of a poor prognosis of patients with MPE.

\section{Materials and methods}

Subjects. Twenty-six patients newly diagnosed with lung cancer with MPE, and 12 patients newly diagnosed with community- 
acquired pneumonia with PPE, who were admitted to the Department of Respiratory Diseases at the First Affiliated Hospital of Zhejiang University from May 2012 to October 2012 were enrolled in the present study. Histologically, all of the patients were diagnosed with adenocarcinoma. A diagnosis of MPE was established by verification of malignant cells in the pleural fluid or/and on closed pleural biopsy specimen. The patients were excluded if they had received any invasive manipulations directed into the pleural cavity or if they had a chest trauma within 3 months prior to hospitalization. Up to the time of sample collection, none of the patients had received any drug that could affect the immune response within 3 months before enrollment. The study was approved by the ethics committee of our institution, and informed consent was obtained from all patients or their surrogates.

Sample collection and processing. The pleural fluid samples were collected within $24 \mathrm{~h}$ of hospitalization in heparin-treated tubes using a standard thoracentesis technique. Following centrifugation at $4,000 \mathrm{rpm}$ for $10 \mathrm{~min}$ at $4^{\circ} \mathrm{C}$, the cell-free supernatants were dispensed into $1.5-\mathrm{ml}$ Eppendorf tubes and frozen at $-80^{\circ} \mathrm{C}$ for the detection of cytokines and chemokines. Then, the cell pellets were resuspended in lysis buffer (BD Biosciences, San Jose, CA, USA) for removal of the red blood cells, and were then analyzed by flow cytometry and real-time PCR.

Flow cytometry of Th17 cells and Tregs. To analyze the perecentage of Th17 cells, IL-17-producing CD4 ${ }^{+}$cells were detected. MNCs $\left(2 \times 10^{6}\right)$ from pleural effusion were stimulated with $50 \mathrm{ng} / \mathrm{ml}$ PMA (BioVision, Mountain View, CA, USA) and $500 \mathrm{ng} / \mathrm{ml}$ ionomycin (Enzo Life Sciences, Farmingdale, NY, USA) in the presence of GolgiPlug (BD Biosciences) for $4 \mathrm{~h}$, after which the cells were stained for FITC-labeled antihuman CD4, then fixed and permeabilized with IC fixation/ permeabilization buffer (eBioscience, San Diego, CA, USA), washed and intracellularly stained with PE-labeled antihuman IL-17.

To detect Tregs, a human regulatory T-cell staining kit (eBioscience) was used according to the manufacturer's protocol. MNCs were surfacely stained with FITC-labeled anti-human CD4 and PE-labeled anti-human CD25 for $30 \mathrm{~min}$ in the dark at $4^{\circ} \mathrm{C}$, then washed and incubated with $1 \mathrm{ml}$ Foxp3 fixation/permeabilization buffer (eBioscience) for $60 \mathrm{~min}$ at $4^{\circ} \mathrm{C}$ in the dark. The cells were washed with $1 \mathrm{ml}$ $1 \mathrm{X}$ permeabilization buffer twice and intracellularly stained using APC-labeled anti-human FoxP3 or an isotype control (PE-labeled rat IgG; BD Biosciences) for $30 \mathrm{~min}$ away from light at $4^{\circ} \mathrm{C}$. Flow cytometry acquisition was performed using an FACSCalibur (BD Biosciences), and data were analyzed using CellQuest software (BD Biosciences).

Real-time PCR of ROR $\gamma t$ and Foxp3 levels. Total RNA was extracted from pleural MNCs using the TRIzol reagent (Invitrogen, Carlsbad, CA, USA) and reverse transcription based on the manufacturer's instructions. Quantitative realtime polymerase chain reaction was performed using the SYBR-Green PCR Mix (Takara, Dalian, China). Cycling reactions were performed using an ABI 7500 Sequence Detection System. The following primer pairs were used: $R O R \gamma t$ : forward, 5'-TGAGAAGGACAGGGAGCCAA-3' and reverse, 5'-CCACAGATTTTGCAAGGGATCA-3'; FoxP3: forward, 5'-GAGAAGCTGAGTGCCATGCA-3' and reverse, 5'-AGAG CCCTTGTCGGATGAT-3'; GAPDH: forward, 5'-GGTCTC CTCTGACTTCAACA-3' and reverse, 5'-GTGAGGGTCTCT CTCTTCCT-3'. The PCR thermal cycle was $95^{\circ} \mathrm{C}$ for $30 \mathrm{sec}$, 40 cycles of $95^{\circ} \mathrm{C}$ for $5 \mathrm{sec}, 60^{\circ} \mathrm{C}$ for $34 \mathrm{sec}$. GAPDH was utilized as a housekeeping gene for normalization, and a deionized water sample was used as a negative control. All reactions were carried out in triplicate per sample.

ELISA measurement of cytokines and chemokines. The levels of cytokines, including IL-6, IL-10, TGF- $\beta 1$ and IL-17 (eBioscience), as well as chemokines CCL17 and CCL20 (R\&D Systems, Minneapolis, MN, USA) in pleural fluids were measured by ELISA kits according to the manufacturer's protocols. All samples were detected in duplicate.

Statistical analysis. Values are expressed as mean \pm SEM. Differences between values were determined using the nonpaired Student's t-test. Correlations between values were evaluated by Spearman's rank correlation coefficients. Survival was assessed by the Kaplan-Meier method and compared by the log-rank test. Analysis was performed with the SPSS Statistical Software (version 21.0; SPSS, Inc., Chicago, IL, USA), and $\mathrm{P}<0.05$ was considered to indicate a statistically significant result.

\section{Results}

Treg/Th17 imbalance exists in MPE. In the present study, flow cytometry was used to investigate the balance of Tregs and Th17 cells, by detecting the percentages of $\mathrm{CD}^{+} \mathrm{IL}-17^{+}$and $\mathrm{CD}^{+} \mathrm{CD} 25^{+} \mathrm{FoxP}^{+}$cells in MPE and PPE. We observed that patients with MPE had a higher percentage of Tregs (Fig. A and C) (MPE vs. PPE: $3.86 \pm 0.50$ vs. $1.09 \pm 0.31 \%, \mathrm{P}=0.0004)$ but a lower level of Th17 cells (MPE vs. PPE: $1.18 \pm 0.16$ vs. $2.52 \pm 0.40 \%, \mathrm{P}=0.0022$ ) than patients with PPE (Fig. 1B and D). Moreover, the ratio of Tregs/Th17 cells was obviously higher in MPE than PPE (MPE vs. PPE: $3.89 \pm 0.61$ vs. $0.39 \pm 0.09, \mathrm{P}=0.0003$ ) (Fig. 1E). Notably, Tregs had a negative correlation with Th17 cells in the pleural effusion $(r=-0.5032$, $\mathrm{P}=0.023)($ Fig. 1F).

Meanwhile, both FoxP3 and ROR $\gamma$ t were determined by real-time PCR in MPE and PPE. We found that Foxp3 mRNA expression level from cells in the pleural effusion was significantly increased in patients with MPE compared to patients with PPE (MPE vs. PPE: $3.05 \pm 0.62$ vs. $0.52 \pm 0.11$, $\mathrm{P}=0.0012$ ) (Fig. 2A). In contrast, ROR $\gamma \mathrm{t}$ mRNA expression presented an opposite result, which was markedly lower in MPE than the level in PPE (MPE vs. PPE: $0.78 \pm 0.23$ vs. $2.19 \pm 0.58, \mathrm{P}=0.0253$ ) (Fig. $2 \mathrm{~B}$ ). The ratio of Foxp3/ROR $\gamma \mathrm{t}$ was significantly higher in MPE as compared with that in PPE (MPE vs. PPE: $14.45 \pm 0.28$ vs. $0.11 \pm 0.05, \mathrm{P}=0.008$ ) (Fig. $2 \mathrm{C}$ ).

Moreover, concentrations of Treg/Th17-related cytokines, IL-10, IL-6, TGF- $\beta 1$ and IL-17, were detected by ELISA. The levels of IL-10 and TGF- $\beta 1$ exhibited increasing trends from MPE to PPE (MPE vs. PPE: IL-10, 166.3 \pm 39.53 vs. $40.38 \pm 10.92 \mathrm{pg} / \mathrm{ml}, \mathrm{P}=0.0307$; TGF- $\beta 1,10,720 \pm 1,274$ vs. $17,47 \pm 293.2 \mathrm{pg} / \mathrm{ml}, \mathrm{P}<0.0001$ ) (Fig. $3 \mathrm{~A}$ and B). In contrast, 
A

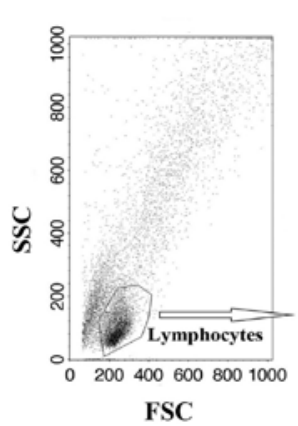

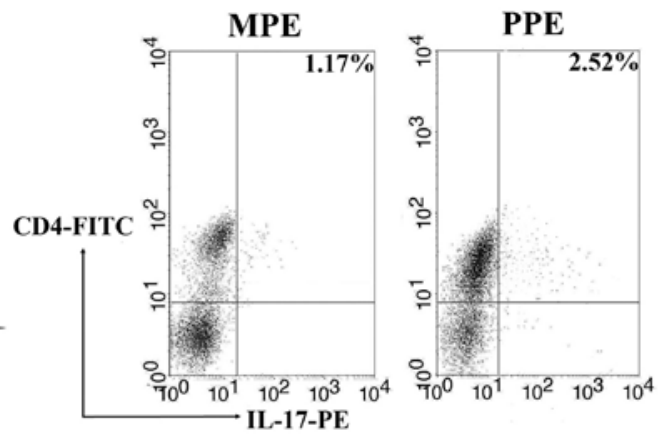

B
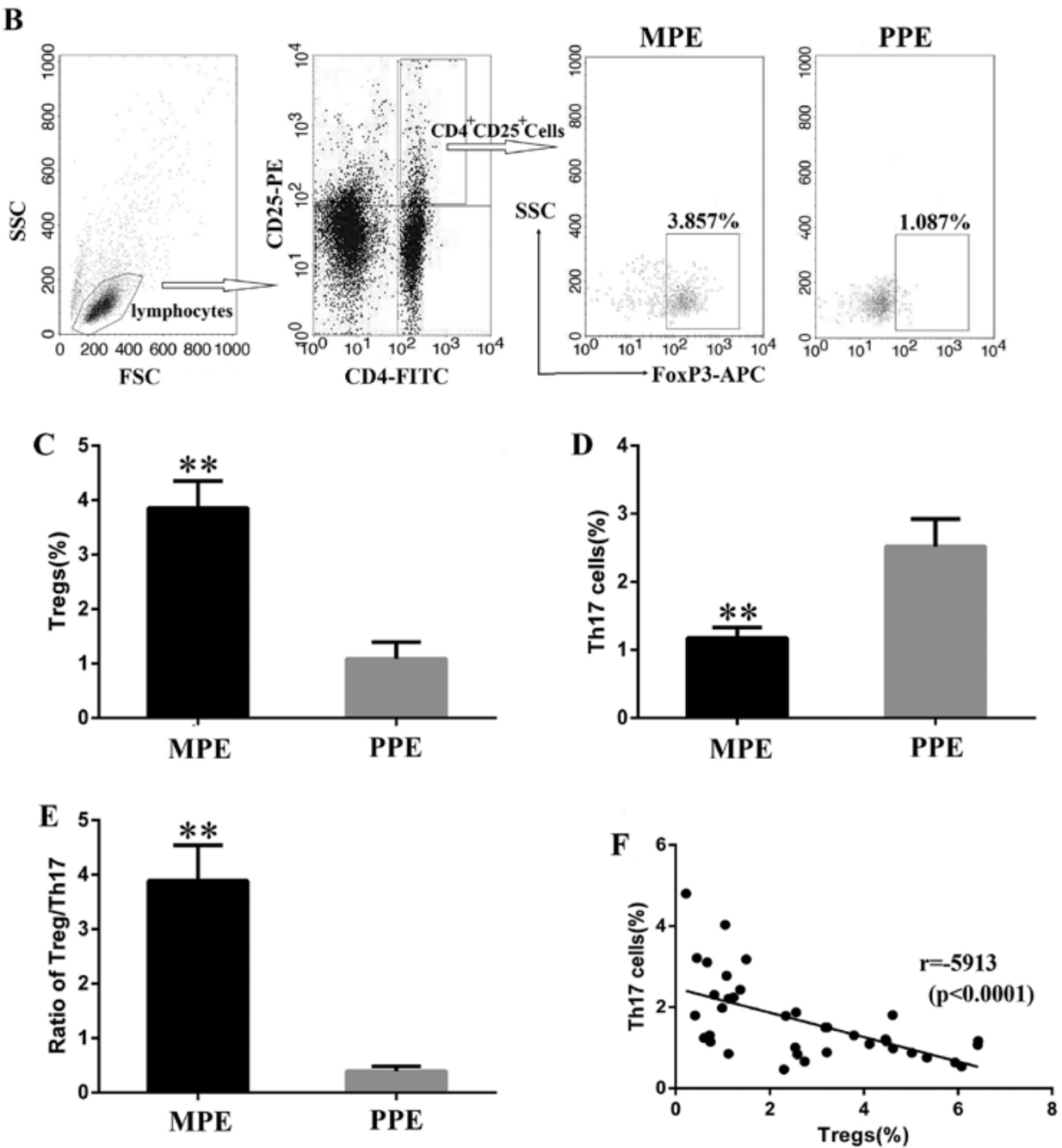

Figure 1. Tregs and Th17 cells in MPE $(n=26)$ and PPE $(n=12)$. (A and C) Percentage of Tregs $\left(C D 4^{+} \mathrm{CD} 25^{+} \mathrm{FoxP} 3^{+}\right.$cells). (B and D) Percentage of Th17 cells (CD4 $4^{+} \mathrm{IL}-17^{+}$cells). (E) Comparison of the of Treg/Th17 ratio in MPE and PPE. The ratio of Tregs/Th17 cells was higher in MPE than the ratio in PPE. (F) Tregs were found to be negatively correlated with Th17 cells in pleural effusion. ${ }^{* *} \mathrm{P}<0.01$, patients with MPE vs. patients with PPE.
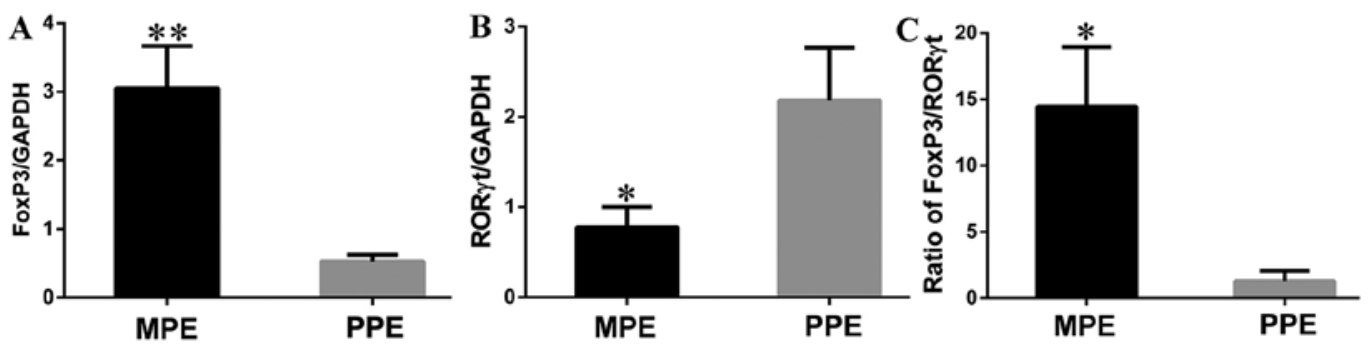

Figure 2. Expression of transcription factors in MPE ( $n=26)$ and PPE $(n=12)$. (A) Relative expression of FoxP3 was compared between the patients with MPE and PPE. (B) Relative expression of ROR $\gamma$ was compared between the patients with MPE and PPE. (C) Comparison of the FoxP3/ROR $\gamma$ ratio in MPE and PPE. The ratio of FoxP3/ROR $\gamma$ was higher in MPE than the ratio in PPE. ${ }^{* *} \mathrm{P}<0.01,{ }^{*} \mathrm{P}<0.05$, patients with MPE vs. patients with PPE. 
A
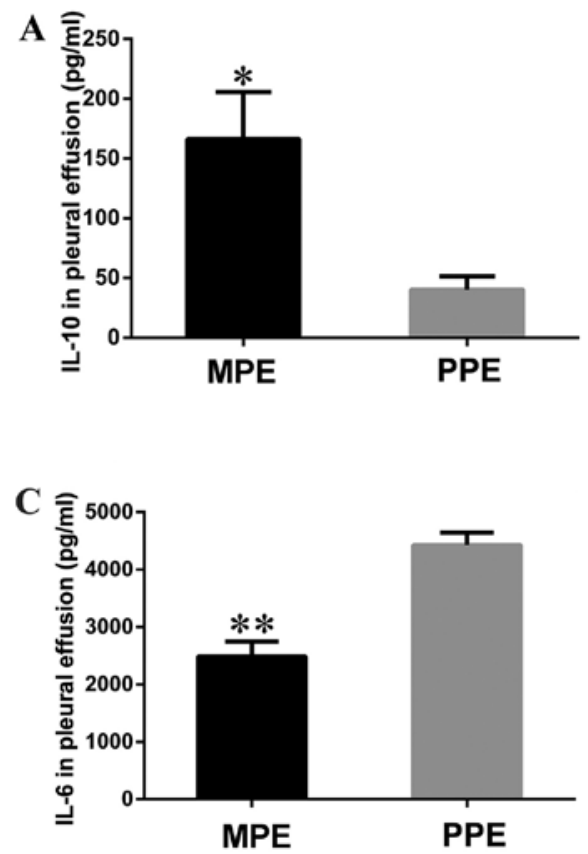

B
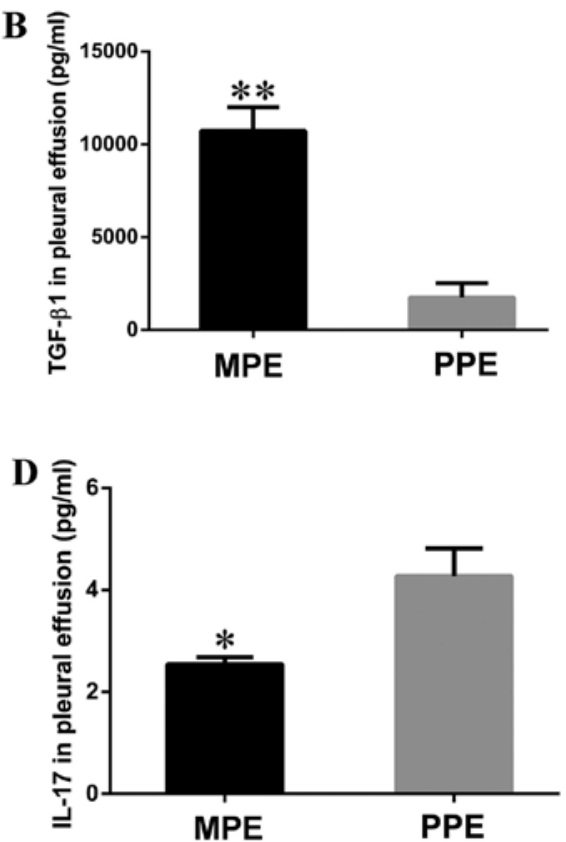

Figure 3. Concentrations of cytokines in pleural effusion. The concentrations of (A) IL-10 and (B) TGF- $\beta 1$ presented an increasing trend from MPE to PPE, while the levels of (C) IL-6 and (D) IL-17 exhibited a relative decreasing trend. ${ }^{* *} \mathrm{P}<0.01,{ }^{*} \mathrm{P}<0.05$, patients with MPE vs. patients with PPE.

\section{A}
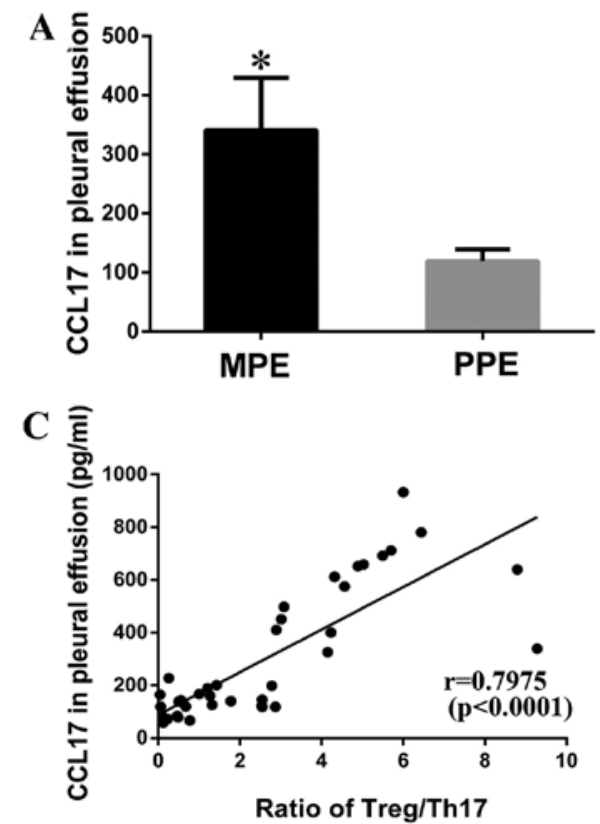

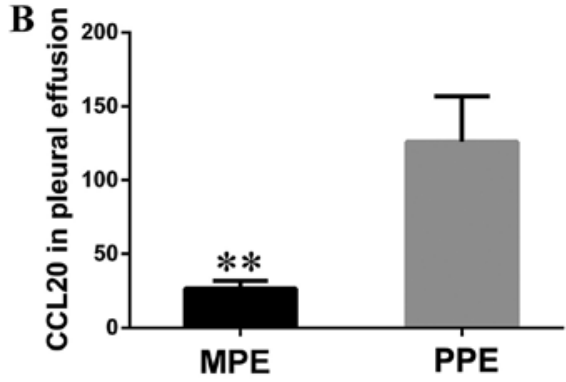

D $\overline{\bar{\varepsilon}}$

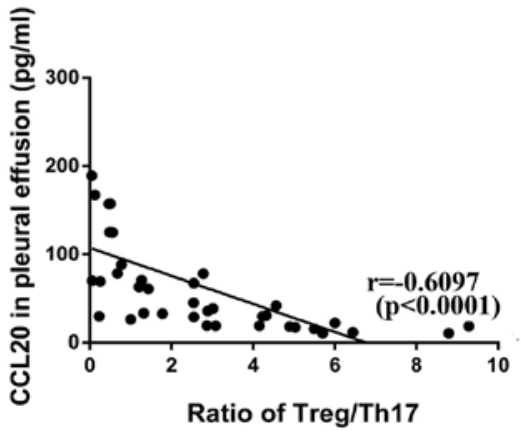

Figure 4. Chemokines (A) CCL17 and (B) CCL20 in MPE and PPE. ${ }^{* *} \mathrm{P}<0.01,{ }^{*} \mathrm{P}<0.05$, patients with MPE vs. patients with PPE. (C) A positive correlation was noted between the level of CCL17 and the ratio of Tregs/Th17 cells; (D) while a negative correlation was noted between the level of CCL20 and ratio of Tregs/Th17 cells.

the levels of IL-6 and IL-17 exhibited a relative decreasing

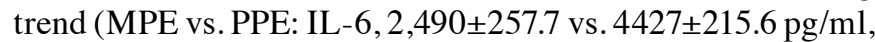
$\mathrm{P}<0.0001$; IL-17, $2.542 \pm 0.1408$ vs. $4.272 \pm 0.5413 \mathrm{pg} / \mathrm{ml}$, $\mathrm{P}=0.0148)$ (Fig. 3C and D).

Alteration of CCL17 and CCL20 may be responsible for the Treg/Th17 imbalance in MPE. Previous studies demonstrated that CCL17 induce the migration of Tregs (12), while CCL20 exerts a potent chemoattractant activity for Th17 cells (8). We measured CCL17 and CCL20 by ELISA and showed that a higher level of CCL17 (MPE vs. PPE: 341.10 \pm 88.22 vs. $119.20 \pm 19.80 \mathrm{pg} / \mathrm{ml}, \mathrm{P}=0.0427$ ) and a lower level of CCL20 (MPE vs. PPE: $26.51 \pm 5.32$ vs. $125.90 \pm 30.89 \mathrm{pg} / \mathrm{ml}, \mathrm{P}=0.0039$ ) were noted in MPE in contrast to these levels in PPE (Fig. 4A and B). Importantly, there was a positive correlation between the level of CCL17 and the ratio of Tregs/Th17 cells ( $r=0.7975$, 
Table I. Characteristics of the patients with MPE.

\begin{tabular}{lrrr}
\hline Characteristics & $\mathrm{N}$ & Mean \pm SEM & Median (range) \\
\hline Gender & & & \\
$\quad$ Male & 14 & & $66(42-83)$ \\
Female & 12 & $63.77 \pm 2.53$ & $40.88(31.77-70.20)$ \\
Age (years) & 26 & $42.10 \pm 1.71$ & $388.5(129-1596)$ \\
Protein (g/l) & 26 & $494.4 \pm 75.9$ & $214.7(1.4-1388)$ \\
Lactate dehydrogenase (LDH, U/l) & 26 & $345.1 \pm 78.1$ & $1.41(0.72-3.62)$ \\
Carcinoembryonic antigen $(\mathrm{CEA}, \mathrm{ng} / \mathrm{ml})$ & 26 & $1.51 \pm 0.14$ & $45.00(10-90)$ \\
Total cell count, $x 10^{9} / 1$ & 26 & $48.85 \pm 5.01$ & $3.54(1.00-9.28)$ \\
Lymphocytes, $\%$ & 26 & $3.89 \pm 0.61$ & \\
Tregs/Th17 cells & 26 & & \\
\hline
\end{tabular}

Table II. Univariate and multivariate analyses of the correlation between factors of the patients with MPE and survival.

\begin{tabular}{lccc}
\hline & Univariate & & \multicolumn{2}{c}{ Multivariate } \\
\cline { 2 - 3 } Variables & P-value & Hazard ratio & $95 \%$ CI \\
\hline Gender & 0.612 & & \\
Age (years) & 0.405 & & \\
Protein & 0.863 & & \\
Total cell count & 0.671 & & \\
Lymphocytes & 0.119 & 1.975 & $0.764-5.106$ \\
LDH & 0.042 & 0.717 & $0.315-1.633$ \\
CEA & 0.022 & 0.094 & $0.026-0.348$ \\
Treg/Th17 & 0.0003 & & 0.428 \\
\hline
\end{tabular}

LDH, lactate dehydrogenase; CEA, carcinoembryonic antigen; CI, confidence interval.

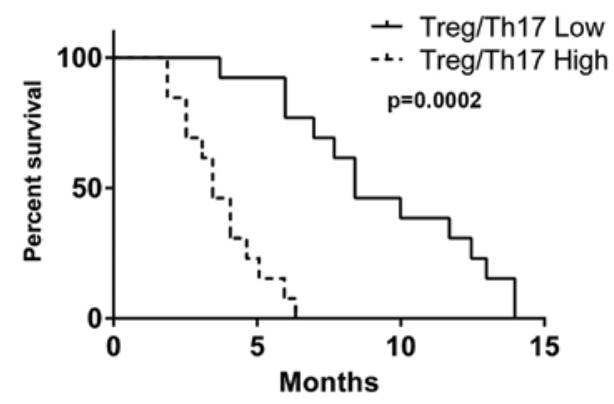

Figure 5. Higher Treg/Th17 ratio predicts poor survival in patients with MPE. Patients with a higher Treg/Th17 ratio $(n=13)$ had a significantly shorter survival than those with a lower Treg/Th17 ratio $(\mathrm{n}=13)$. Overall survival was analyzed by the Kaplan-Meier method and compared by the log-rank test.

$\mathrm{P}<0.0001$ ) (Fig. 4C), but a negative correlation between the level of CCL20 and the ratio of Tregs/Th17 cells ( $r=-0.6097$, $\mathrm{P}<0.0001$ ) (Fig. 4D).

Higher Treg/Th17 ratio predicts the poor survival of patients with MPE. The characteristics of patients with MPE and the measurement of pleural effusion were listed in Table I. To test whether a Treg/Th17 imbalance impacted the prognosis of patients with MPE, we analyzed the correlation of overall survival time with the Treg/Th17 ratio in 26 patients with MPE. Subjects were divided into two equal groups according to the ratio of Tregs/Th17 cells. The low group included all those with a Treg/Th17 ratio $<3.54 \%(n=13)$ and the high group included those with a Treg/Th17 ratio $>3.54 \%(n=13)$. As shown in Fig. 5, there was a significant correlation between the pleural Treg/Th17 ratio and survival $(\mathrm{P}=0.0002)$. Patients with a higher Treg/Th17 ratio had a significantly shorter overall survival (median, 3.4 months) than patients with a lower Treg/Th17 ratio (median, 6.7 months). Patients with MPE in the higher Treg/Th17 ratio group experienced a 9-fold higher death hazard as compared with those in the lower Treg/ Th17 ratio group (95\% confidence interval, 3.12-26.26). The multivariate Cox proportional hazards analysis revealed that the Treg/Th17 ratio was an independent prognostic factor for survival (hazard ratio $=0.094 ; \mathrm{P}<0.001$ ) (Table II). However, the levels of lactate dehydrogenase (LDH) and carcinoembryonic antigen (CEA) were not independent prognostic factors for survival $(\mathrm{P}>0.05)$. Thus, we considered that an increase in the Treg/Th17 ratio was related to high risk for death and for poor survival in patients with MPE. 


\section{Discussion}

In recent years, the balance of Th17 and Treg cells, and the regulatory mechanisms between $\mathrm{T}$ cell subsets in the pathogenesis of pleural effusion have attracted more and more attention. The present study focused on the comparison of function of these two new subsets between MPE and PPE and showed that lung cancer patients with MPE exhibited a marked elevation in the percentage of Tregs, IL-10, TGF- $\beta 1$ and Foxp3 mRNA levels, and a marked decline in the percentage of Th17 cells, IL-6, IL-17 and ROR $\gamma \mathrm{t}$ mRNA levels in contrast to those with PPE. The imbalance of the Treg/Th17 ratio may provide a mechanistic insight into immunomodulation involved in MPE.

Treg cells have been broadly considered as a critical subset of $\mathrm{T}$ cells which execute their suppressive function against $\mathrm{T}$ cell-mediated immune response and play an important role in peripheral tolerance, autoimmunity and tumor immunity (13). Studies have confirmed the accumulation of Tregs in tumor tissues and peripheral blood of tumor-bearing animals and patients with cancer, and such an increase in Tregs predict a grim prognosis in cancer $(14,15)$. Thus, Treg cells have the potential to prevent the host from launching an immune response to tumor antigens (16), subsequently facilitating tumor progression. In MPE, overrepresentation of Tregs also exist (17), which is consistent with our findings that the tumor microenvironment may induce more Tregs to gather in the pleural cavity compared with inflammation.

Since the identification of Th17 cells in 2005 (18), their contributions to tumor immunity have been extensively explored. However, these studies have yielded controversial results. The protumor function mediated by Th17 and IL-17 has been proven both in animal tumor models and in patients with cancer $(19,20)$. Th17 cells characteristically produce IL-17 which acts as an angiogenic factor that accelerates tumor growth and metastasis through neovascularization (21). Meanwhile, Th17 cells induce the secretion of inflammatory cytokines, such as IL-8 and TNF- $\alpha$, that attract neutrophil recruitment and destroy the niche of immunity $(22,23)$. However, the role of Th17 in tumors is hardly conclusive. Adequate evidence has proven that Th17 may contribute to protective tumor immunity via stimulating the production of Th1-type chemokines CXCL9 and CXCL10 to recruit effector cells to tumor tissues (10). Th17 cells can also facilitate dendritic cell (DC) accumulation and elicit activation of tumor-specific $\mathrm{CD} 8^{+} \mathrm{T}$ cells, exerting antitumor immunity (24). More recently, Ye et al (11) showed that the number of Th17 cells was significantly increased in MPE, which predicted prolonged survival, implying a beneficial role for Th17 cells in human cancer.

It has been well demonstrated that the developmental processes of Tregs and Th17 cells are reciprocally interactive (25). The deviated balance of TGF- $\beta$ and IL- 6 might control the switch of Tregs or Th17 cells via antagonistic competition of Foxp3 and ROR $\gamma \mathrm{t}$ (26). In this process, TGF- $\beta$ induces both Foxp3 and ROR $\gamma \mathrm{t}$ expression, but exclusively converts naïve T cells into Treg cells (27), while IL-6 can abrogate the inhibition of ROR $\gamma \mathrm{t}$ by Foxp3 and initiate the differentiation of Th17 cells (28). In MPE, we found that the numbers of Tregs and Th17 cells were inversely correlated, and both the ratios of Tregs/Th17 cells and Foxp3/ROR $\gamma$ t were markedly lower in MPE than in PPE, suggesting a close interplay between
Tregs and Th17 cells in tumor development, and that the Treg/Th17 ratio might be a valuable index in the differentiation of malignant from benign pleural effusion. Furthermore, we investigated the levels of cytokines associated with Tregs and Th17 cells in pleural effusion. In the present study, higher levels of TGF- $\beta 1$ and IL-10, but lower levels of IL- 6 and IL-17 were in MPE in contrast to that in PPE. TGF- $\beta$ and IL-10, serving as negative regulators, might promote tumor progression through inducing immunosuppression and assisting in evasion from tumor immune surveillance $(29,30)$.

Chemokines with chemoattracting and activating properties play pivotal roles in tumor immunity. CCL17 in the tumor microenvironment is related to Treg cells in lung carcinomas, gastric carcinomas and ovarian carcinomas $(12,31,32)$. Such tumor-infiltrating Treg cells trigger impaired tumor-specific immune responses and unfavorable prognosis (33). CCL20 has been shown to serve as an immunotherapeutic mediator which can cause accumulation in DCs and $\mathrm{CD}^{+}$cells into the tumors and suppress tumor growth (33). Ye and the coworkers (11) demonstrated that CCL20 in MPE might contribute to chemoattract Th17 cells into the pleural space. Our results suggest that CCL17, rather than CCL20, exerted a dominant effect on Treg cell infiltration in MPE.

Additionally, we evaluated the relationship between the ratio of Tregs/Th17 cells and clinical pathological parameters in MPE. Herein, we noted that a higher Treg/Th17 ratio predicted worse survival, implying that the balance of Treg/Th17 might be a significant prognostic factor for tumor progression.

In conclusion, our data showed that the ratio of Tregs/Th17 cells was increased in MPE in contrast to that in PPE, which is valuable for the differential diagnosis of pleural effusion. Alteration of CCL17 and CCL20 might be responsible for the Treg/Th17 imbalance in MPE. The Treg/Th17 imbalance might be involved in the development of MPE and a higher Treg/Th17 ratio predicted the poor prognosis of patients with MPE.

\section{Acknowledgements}

The present study was supported by grants from the Major Project of the Science Technology Department of Zhejiang Province, China (no. 2012C13022-2), the Project of Health and Family Planning Commission of Zhejiang Province, China (no. 2013KYB105), and the Key Personnel of Zhejiang Medicine and Health Platform (no. 2012RCA025).

\section{References}

1. Roberts ME, Neville E, Berrisford RG, Antunes G and Ali NJ: BTS Pleural Disease Guideline Group: Management of a malignant pleural effusion: British Thoracic Society Pleural Disease Guideline 2010. Thorax 65: ii32-ii40, 2010.

2. Bielsa S, Martín-Juan J, Porcel JM and Rodríguez-Panadero F: Diagnostic and prognostic implications of pleural adhesions in malignant effusions. J Thorac Oncol 3: 1251-1256, 2008.

3. Marazioti A, Blackwell TS and Stathopoulos GT: The lymphatic system in malignant pleural effusion. Drain or immune switch? Am J Respir Crit Care Med 189: 626-627, 2014.

4. Aguiar LM, Antonangelo L, Vargas FS, Zerbini MC, Sales MM, Uip DE and Saldiva PH: Malignant and tuberculous pleural effusions: immunophenotypic cellular characterization. Clinics (Sao Paulo) 63: 637-644, 2008. 
5. Muller YD, Seebach JD, Bühler LH, Pascual M and Golshayan D: Transplantation tolerance: clinical potential of regulatory T cells. Self Nonself 2: 26-34, 2011.

6. Gregori S, Bacchetta R, Passerini L, Levings MK and Roncarolo MG: Isolation, expansion, and characterization of human natural and adaptive regulatory cells. Methods Mol Biol 380: 83-106, 2007.

7. Wilke CM, Wu K, Zhao E, Wang G and Zou W: Prognostic significance of regulatory $\mathrm{T}$ cells in tumor. Int $\mathrm{J}$ Cancer 127: 748-758, 2010.

8. Qin XJ, Shi HZ, Deng JM, Liang QL, Jiang J and Ye ZJ: CCL22 recruits $C D 4$-positive $C D 25$-positive regulatory $T$ cells into malignant pleural effusion. Clin Cancer Res 15: 2231-2237, 2009.

9. Bettelli E, Oukka M and Kuchroo VK: $\mathrm{T}_{\mathrm{H}}-17$ cells in the circle of immunity and autoimmunity. Nat Immunol 8: 345-350, 2007.

10. Kryczek I, Banerjee M, Cheng P, et al: Phenotype, distribution, generation, and functional and clinical relevance of Th17 cells in the human tumor environments. Blood 114: 1141-1149, 2009.

11. Ye ZJ, Zhou Q, Gu YY, et al: Generation and differentiation of IL-17-producing $\mathrm{CD}^{+} \mathrm{T}$ cells in malignant pleural effusion. J Immunol 185: 6348-6354, 2010.

12. Mizukami Y, Kono K, Kawaguchi Y, Akaike H, Kamimura K, Sugai $\mathrm{H}$ and Fujii H: CCL17 and CCL22 chemokines within tumor microenvironment are related to accumulation of Foxp3 regulatory T cells in gastric cancer. Int J Cancer 122: 2286-2293, 2008.

13. Lin X, Chen M, Liu Y, Guo Z, He X, Brand D and Zheng SG: Advances in distinguishing natural from induced Foxp3 ${ }^{+}$regulatory T cells. Int J Clin Exp Pathol 6: 116-123, 2013.

14. Larmonier N, Marron M, Zeng Y, et al: Tumor-derived $\mathrm{CD} 4{ }^{+} \mathrm{CD} 25^{+}$regulatory $\mathrm{T}$ cell suppression of dendritic cell function involves TGF-beta and IL-10. Cancer Immunol Immunother 56: 48-59, 2007.

15. Badoual C, Hans S, Rodriguez J, et al: Prognostic value of tumorinfiltrating $\mathrm{CD}^{+} \mathrm{T}$-cell subpopulations in head and neck cancers Clin Cancer Res 12: 465-472, 2006

16. Kosmaczewska A, Ciszak L, Potoczek S and Frydecka I: The significance of Treg cells in defective tumor immunity. Arch Immunol Ther Exp (Warsz) 56: 181-191, 2008.

17. Ibrahim L, Salah M, Rahman AA,Zeidan A and Ragb M: Crucial role of $\mathrm{CD} 4^{+} \mathrm{CD} 25^{+} \mathrm{FOXP}^{+} \mathrm{T}$ regulatory cell, interferon- $\gamma$ and interleukin-16 in malignant and tuberculous pleural effusions. Immunol Invest 42: 122-136, 2013.

18. Harrington LE, Hatton RD, Mangan PR, Turner H, Murphy TL Murphy KM and Weaver CT: Interleukin 17-producing CD4 effector T cells develop via a lineage distinct from the Thelper type 1 and 2 lineages. Nat Immunol 6: 1123-1132, 2005.
19. Prabhala RH, Pelluru D, Fulciniti M, et al: Elevated IL-17 produced by TH17 cells promotes myeloma cell growth and inhibits immune function in multiple myeloma. Blood 115: 5385-5392, 2010

20. Tosolini M, Kirilovsky A, Mlecnik B, et al: Clinical impact of different classes of infiltrating T cytotoxic and helper cells (Th1, th2, treg, th17) in patients with colorectal cancer. Cancer Res 71: 1263-1271, 2011

21. Qi W, Huang X and Wang J: Correlation between Th17 cells and tumor microenvironment. Cell Immunol 285: 18-22, 2013.

22. Iida T, Iwahashi M, Katsuda M, et al: Tumor-infiltrating CD4+ Th17 cells produce IL-17 in tumor microenvironment and promote tumor progression in human gastric cancer. Oncol Rep 25: 1271-1217, 2011.

23. Gu FM, Li QL, Gao Q, et al: IL-17 induces AKT-dependent IL-6/ JAK2/STAT3 activation and tumor progression in hepatocellular carcinoma. Mol Cancer 10: 150, 2011.

24. Martin-Orozco N, Muranski P, et al: $\mathrm{T}$ helper 17 cells promote cytotoxic $\mathrm{T}$ cell activation in tumor immunity. Immunity 31 : 787-798, 2009.

25. Ayyoub M, Deknuydt F, Raimbaud I, Dousset C, Leveque L, Bioley $\mathrm{G}$ and Valmori D: Human memory FOXP $3^{+}$Tregs secrete IL-17 ex vivo and constitutively express the $T_{H} 17$ lineage- specific transcription factor ROR $\gamma$ t. Proc Natl Acad Sci USA 106: 8635$8640,2009$.

26. Weaver CT and Hatton RD: Interplay between the TH17 and TReg cell lineages: a (co-) evolutionary perspective. Nat Rev Immunol 9: 883-889, 2009.

27. Zhou L, Lopes JE, Chong MM, et al: TGF-beta-induced Foxp3 inhibits $\mathrm{T}_{\mathrm{H}} 17$ cell differentiation by antagonizing ROR $\gamma \mathrm{t}$ function. Nature 453: 236-240, 2008.

28. Kimura A and Kishimoto T: IL-6: regulator of Treg/Th17 balance. Eur J Immunol 40: 1830-1835, 2010.

29. Smith AL, Robin TP and Ford HL: Molecular pathways: targeting the TGF- $\beta$ pathway for cancer therapy. Clin Cancer Res 18: 4514-4521, 2012

30. Hamidullah, Changkija B and Konwar R: Role of interleukin-10 in breast cancer. Breast Cancer Res Treat 133: 11-21, 2012.

31. Olkhanud $\mathrm{PB}$, Baatar D, Bodogai M, et al: Breast cancer lung metastasis requires expression of chemokine receptor CCR4 and regulatory T cells. Cancer Res 69: 5996-6004, 2009.

32. Curiel TJ, Coukos G, Zou L, et al: Specific recruitment of regulatory $\mathrm{T}$ cells in ovarian carcinoma fosters immune privilege and predicts reduced survival. Nat Med 10: 942-949, 2004.

33. Franciszkiewicz K, Boissonnas A, Boutet M, Combadière $C$ and Mami-Chouaib F: Role of chemokines and chemokine receptors in shaping the effector phase of the antitumor immune response. Cancer Res 72: 6325-6332, 2012. 